\title{
PROGRESS IN THERMO-ABRASIVE BLASTING SYSTEMS
}

\author{
I.A. Gorlach \\ Department of Industrial Engineering \\ Nelson Mandela Metropolitan University, South Africa \\ igor.gorlach@,nmmu.ac.za
}

\begin{abstract}
Quality of surface preparation of components and structures for further painting and/or coating is important in many fields of engineering. One of the most widely used methods of surface preparation is abrasive blasting. In the last few years, a new method for surface preparation has evolved, namely thermo-abrasive blasting. This technique utilises a high enthalpy thermal jet, generated by the thermo-abrasive blasting gun, to propel abrasive particles. Thermo-abrasive blasting has a number of advantages over conventional abrasive blasting, which were assessed during trials. This paper describes a progress in the applications of thermo-abrasive blasting as well as future potentials for South African industry. The performance data and economic comparison of conventional and thermo-abrasive blasting are also presented in this paper.
\end{abstract}

\section{OPSOMMING}

Die gehalte van voorbereiding van komponent- en struktuuroppervlaktes is oral belangrik in ingenieurswesetoepassings. Wat vrywel tot die hede dikwels gebruik was, is straalskuring. Onlangs het 'n nuwe metode tot stand gekom naamlik termostraalskuring. Die metode maak gebruik van 'n hoë entalpie termostaat om skuurmiddel aan te dryf. Die nuwe metode besit sekere voordele in vergelyking met tradisionele straalskuring. Praktykbevestiging is hiervan met toetse verkry. Hierdie stuk bespreek ook die praktyktoepassings van termostraalskuring en die gepaardgaande voordele vir die Suid-Afrikaanse nywerheid. Toepassingsdata en ekomiese vergelyking van konvensionele- en termostraalskuring word ook behandel. 


\section{INTRODUCTION}

\subsection{Background}

The increasingly competitive world market demands shorter throughput times for products and services. Metal fabrication requires the preparation of surfaces for painting, coating and other processes. Therefore, the target for the surface preparation industry is to clean the manufactured steel in the shortest possible time and to provide good surface quality for adhesion of paints and other coatings.

Abrasive blasting is the most common method of surface preparation. Conventional abrasive blasting methods use a stream of high velocity air to propel abrasives against the surface to be cleaned. In a conventional system, compressed air is supplied to a pressure blast unit and blasting hoses. Abrasives are forced out of the pressure blast unit by the air into the hose and out through a blasting nozzle. The blasting nozzle accelerates the abrasive particles, which in turn bombard a surface, thereby removing scale and coatings.

Conventional abrasive blasting methods are inefficient when the coating to be removed is hard or elastic like rubber or polyurethane. However, the biggest drawback of conventional sandblasting is moisture and impurities introduced by the compressor, which contaminate cleaned surfaces.

In the 1980 `s, a new method of using a ram-jet engine (Fig. 1) for propelling particles appeared in American and Russian patents [1,2]. This method of abrasive blasting is called thermo-abrasive blasting because combustion is the major source of energy for the propulsion of abrasives. Combustion of fuel releases heat and generates a high temperature pressurized gas, which is directed through a nozzle to form a high velocity flow stream. Modifications of the ram-jet engine, whereby abrasive particles are introduced into the gas flow and accelerated by it, led to the design of an apparatus called the thermo-abrasive gun or in short thermal gun.

The combustion process generated by a thermal gun is classified as High Velocity Air Fuel (HVAF) or High Velocity Oxy Fuel (HVOF) process depending on the oxidizer. HVOF processes have been successfully applied in metal spraying for a decade. HVAF processes, on the other hand, are not used in industry and very little scientific data is available.

Combustion chamber

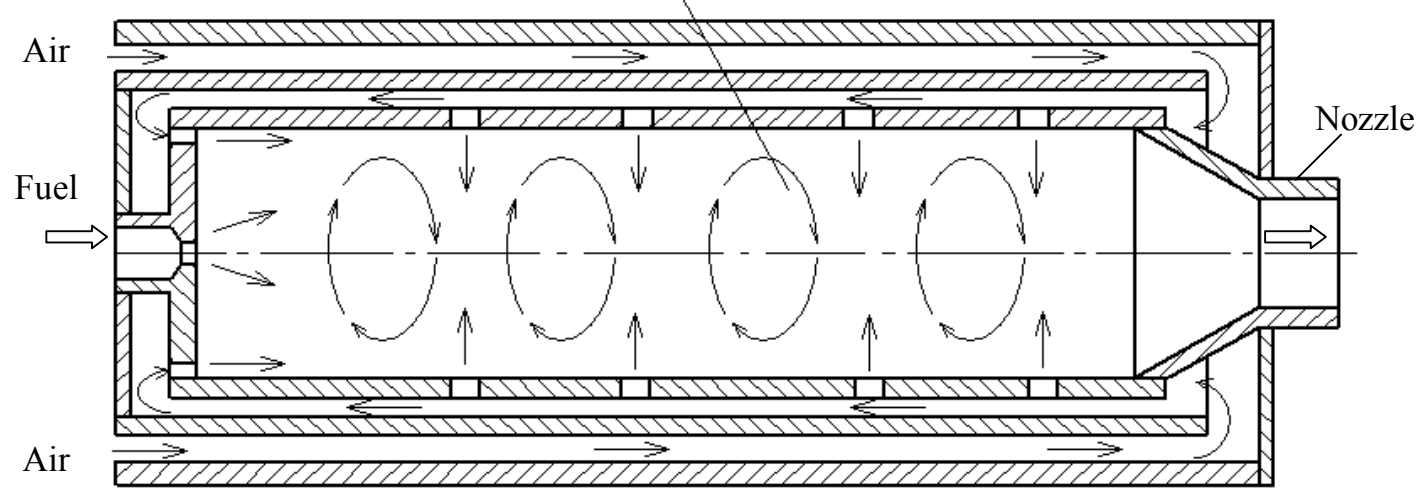

Figure 1: Diagram of a ram jet engine 
In 2000 the author, together with Mr. S. Kotov, developed a thermal gun prototype [3]. This prototype featured a regenerating air supply method similar to a ram-jet engine (Fig. 1) and the abrasive delivery nozzle positioned in the centre of the combustion chamber at some distance from the nozzle, [4]. The thermal gun was tested in industry to assess the performance and possible drawbacks of thermo-abrasive blasting in a real working environment.

\subsection{Problem Statement}

During trials, the following problems associated with an operation of the thermo-abrasive blasting systems were identified:

- Limiting power output of the thermal gun prototype

The thermal gun prototype provided a stable performance and good overall results. However, it was noticed that the power of the thermal gun was limited and could not be increased further even if more fuel was provided. It is believed that the main reasons for this were the way the air and fuel mixed, as well as the small size of the combustion chamber. Furthermore, poor mixing of the fuel and the compressed air did not provide reliable ignition, especially at low temperatures.

\section{- Unreliable ignition}

A small combustion volume and the requirements of mobility create difficulties in designing a compact and efficient ignition system. A high voltage spark gives the highest temperature, which ignites fumes easily. However, the spark plug points may get wet from paraffin, thus insulating them, preventing a spark.

\section{- Difficulty to operate the thermal gun}

Generally, a single operator must be able to control sandblasting equipment. The thermal gun prototype was difficult to operate because it did not have an automated control system.

- Short life of the blasting nozzle

The thermo-abrasive blasting nozzle has a short life due to extreme conditions combining heat, abrasive wear and mechanical stress. This aspect is not discussed in this paper.

\section{LITERATURE SURVEY}

Over two decades attempts were made to produce thermal guns for thermo-abrasive blasting, for example, Browning's thermal gun, Galchenko's thermal gun and Evdokimenko's thermal gun [5]. However, it appears that up to date thermal guns for thermo-abrasive blasting did not find an application in industry.

The closest system in terms of the combustion process to the thermal abrasive gun is a High Velocity Oxy Flame (HVOF) system. HVOF is a process in which a mixture of fuel and oxygen ignites in a high pressure combustion chamber and the combustion products are 
accelerated through a converging - diverging nozzle. A number of studies have been done on the quality of coatings, simulation of the coating process, application of CFD analysis, etc., in the field of metal spraying with HVOF systems. However, on the topic of analytical modelling of a HVOF system there are only few reported studies.

Thermal spraying incorporates a number of processes whereby molten/semi-molten material is deposited at high velocities by gas onto a surface. Typical types of coatings applied to surfaces using thermal spraying are metals, cermets, ceramics, carbides, intermetallics, or a combination of any of these material groups. Wire or fine powders are the most commonly used thermal spraying consumables. Thermal spraying can be divided into two major designs, low or high velocity processes. The biggest difference between high and low velocity processes is the coating quality. Low velocity processes produce coating particle sizes larger than $100 \mu \mathrm{m}$ in diameter. These particles, when they oxidize during application, produce large undesirable oxide structures. With high velocity techniques, the particle sizes are small by comparison, and any oxides formed are of sub-particle size and well bonded between the metal layers. High particle velocities, furthermore, result in better bonding to the substrate. All metal spray applications are done using the high velocity equipment. A schematic of cross section of a thermal spray gun is shown in Figure 2.

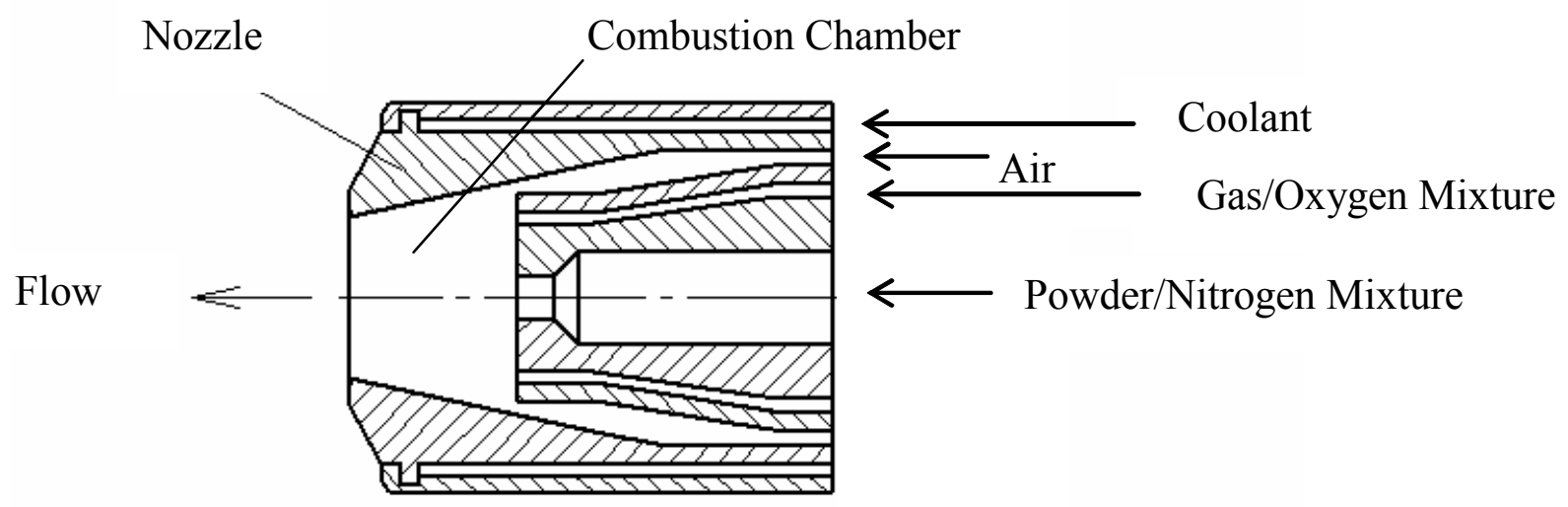

Figure 2: Diagram of a thermal spray gun, Mostaghimi [6]

Reference to HVAF processes could only be found in literature in applications such as thermal spallation, [7]. Thermal spallation is a technique used for drilling through rocks with high-temperature impinging flames. This technique was invented in the middle of the last century. It was extensively used in Siberia and other regions of the former Soviet Union. Thermal spallation has many advantages over mechanical drilling where rapid drill bit wear or expensive diamond cutters can be a problem. In thermal spallation the flames rapidly heat the rocks, which crack due to the extremely high temperature gradients near the surface. Such high gradients cause the rock to crack due to the high thermal stresses. Thermal spallation differs from abrasive blasting due to the considerably higher temperature of the flame. Also, thermal spallation does not employ any abrasive particles. Thermal spallation guns are basically burners with short nozzles, which do not wear and is usually made of heat-resistant steel. An example of the thermal gun for thermal spallation is shown in Figure 3. 


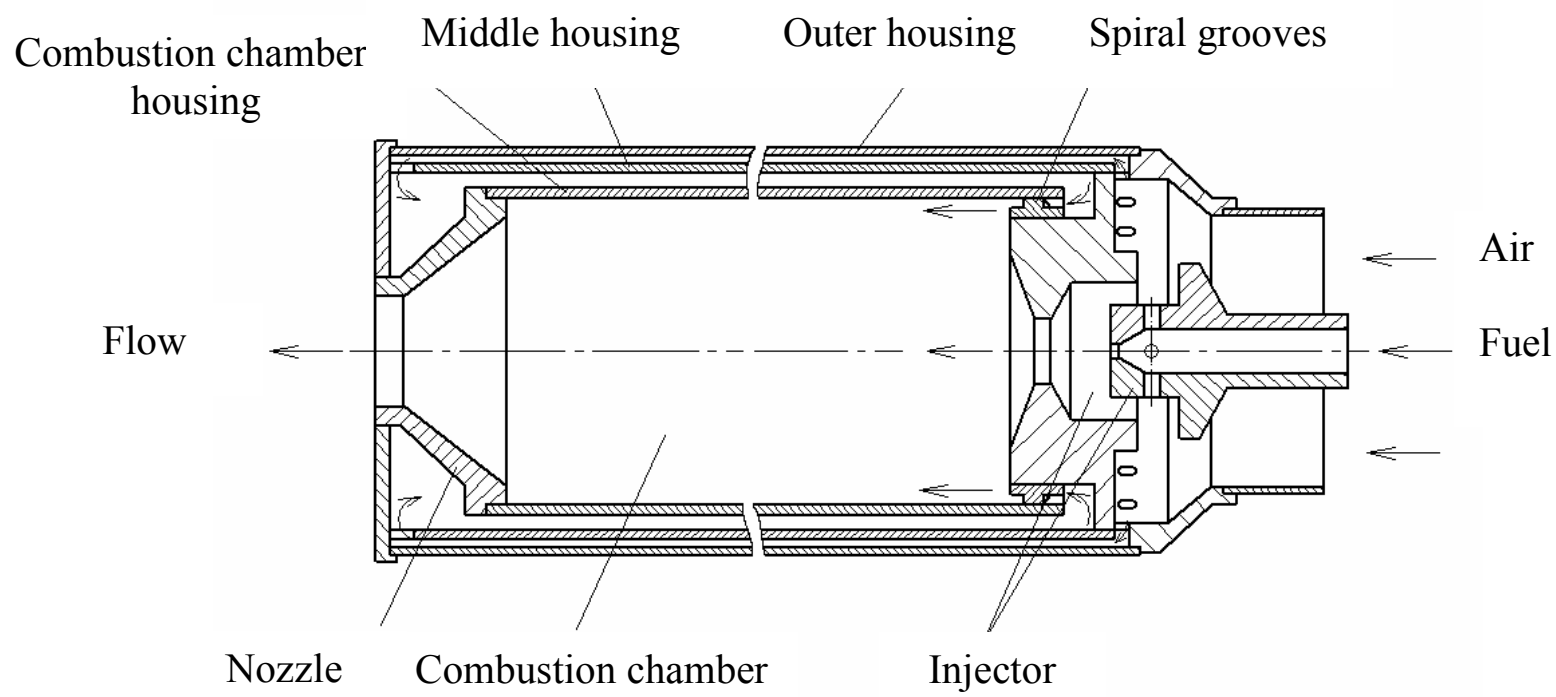

Figure 3: Diagram of Varushin's HVAF gun for thermal spallation

Rauenzahn and Tester [8] studied supersonic flames impinging on rocks in a bore hole. In Rauenzahn's model, the reactant gases were assumed to be at equilibrium, thus the chemical reactions were not modelled. The effect of the chips on the flow field was ignored, so that only single-phase, compressible, axisymmetric, transient fluid flow was modelled. Turbulence was modelled using a combined k- $\varepsilon$ technique in the bulk of flow and the traditional law-of-the-wall in the boundary region. The rock surface temperature was calculated using Weibull's statistical failure theory [9]. The primary objectives of Rauenzahn's [9] study were to find the effects of the standoff distance between the nozzle and the rock and the inlet pressure ratio on the heat transfer and the drilled hole radius.

Wilkinson and Tester [10] studied thermal spallation drilling to further improve the understanding of this phenomenon. The rock temperature was modelled using Dey's thermal spallation rock mechanical model, which is based on a failure mechanism characterized by Weibull's statistical failure theory that requires some empirical parameters. The primary objective was to study the drilling rate and a hole diameter as a function of various parameters, using improved empirical parameters derived from experiments. Compressible, axisymmetric fluid flow and energy equations were discretised using the finite volume formulation. The chemistry was not directly modelled but was simulated by varying the gas properties.

Rauenzahn, Tester and Wilkinson's work mainly concentrated on the relationship between the heat and rate of drilling in thermal spallation. Their models did not take into account chemistry and combustion reactions, and only 2-D single-phase flow was simulated. No particle simulation was included because it was not required for the simulation of the thermal spallation of rocks.

Browning [1] proposed a HVOF thermal gun for abrasive blasting where part of the air is separated from the air/abrasive mixture and used for stabilising the combustion process (Fig. 4). The other distinct feature of the burner is a combustion chamber which is perpendicular to the flow of abrasives. The burner works on fuel and oxygen. The burner has 
a tubular, slotted sand separator that permits air free of sand to pass along the rear side through a bend to the combustion chamber. According to Browning [1], the air entering the combustion chamber through the radial holes stabilises the combustion.

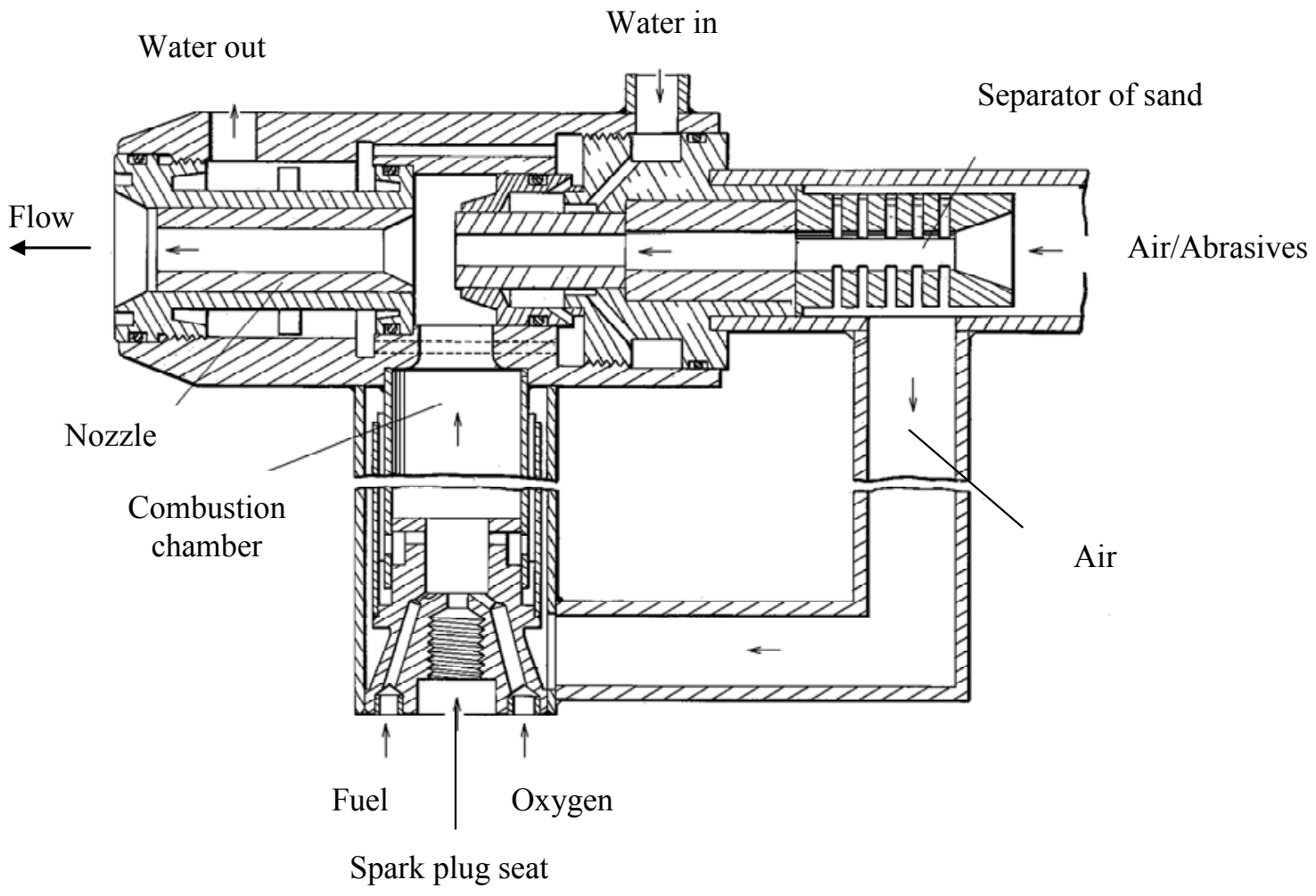

Figure 4: Diagram of Browning's HVOF thermal gun

The position of the combustion chamber perpendicular to the air/abrasive flow would result in turbulence, which would reduce the flow velocity. The use of a sand separator, in the above patent, implies that all the abrasive particles must be relatively large, which is impractical. In addition, the apparatus requires pure oxygen for operation and water for cooling.

The HVAF thermal gun, shown in Figure 5, was presented by Galchenko [2]. This thermal gun has a regenerating cooling system, meaning that the main volume of air is used for combustion and for cooling of the parts, especially the nozzle. The blasting nozzle has a wide, but short, diverging section. The main disadvantage of this thermal gun is that it does not give sufficient mixing of air and fuel, because the air, after passing between two chambers, is losing pressure and does not enter through the spiral grooves of the injector.

The author has built a similar thermal gun and tested it. It was found in experiments that the thermal gun had unstable combustion and a low thrust.

The HVAF thermal gun shown in Figure 6 was presented by Evdokimenko [5] in a US patent 5607342. Referring to Figure 6, the high velocity flame jet apparatus includes a supersonic gun with a main combustion chamber having two parts, one of which is air-cooled and the other of which is water cooled. The air-cooled portion of the chamber is provided with radial air inlet holes to allow the cooling air to enter the chamber and stabilize combustion. 


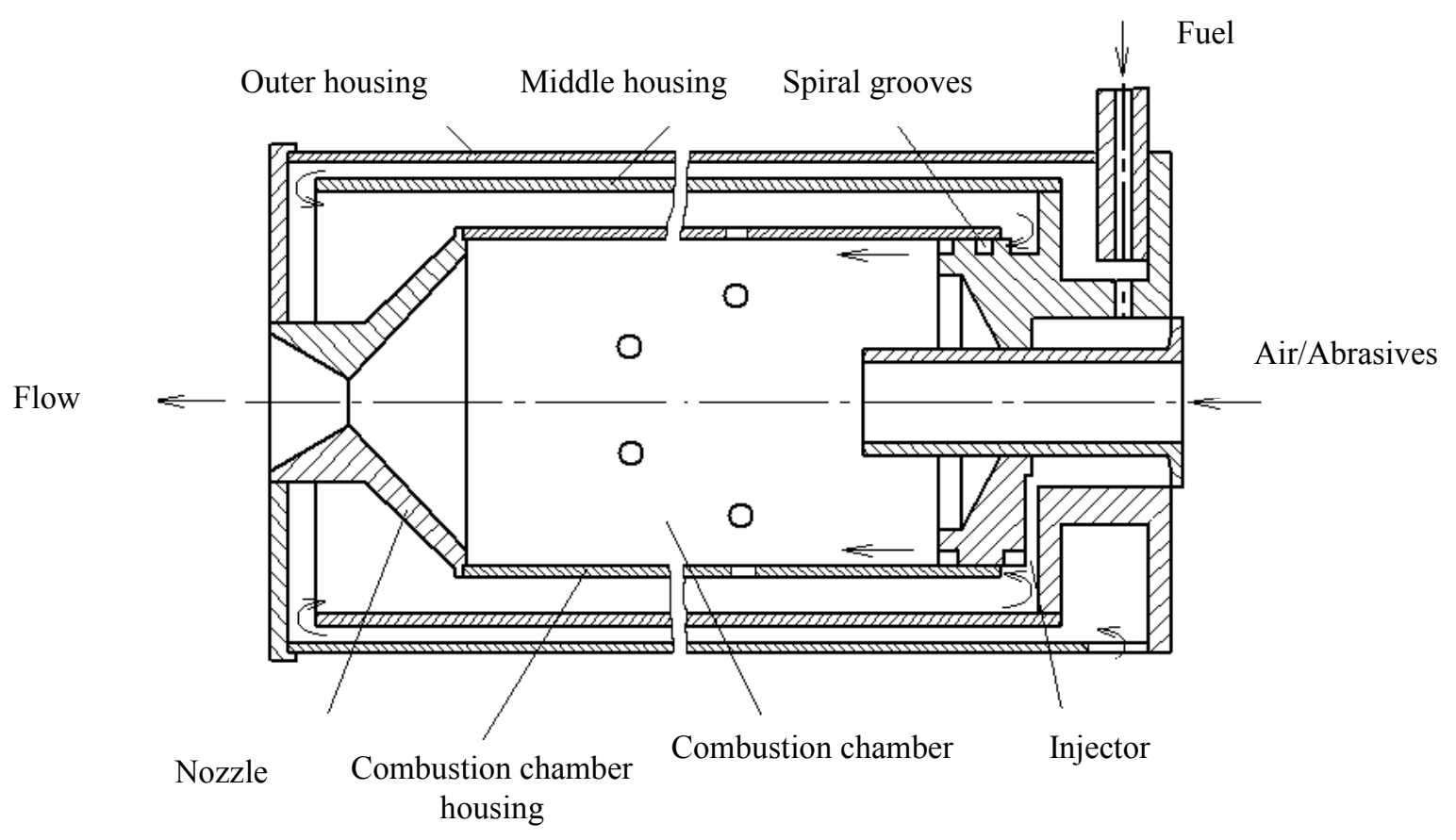

Figure 5: Diagram of Galchenko's HVAF thermal gun

The water-cooled portion of the chamber is elongated and terminates in a bend. A powder sprayer is arranged axially in the bent end of the combustion chamber and a removable exit nozzle is coupled to the end of the combustion chamber. Different nozzles are used for abrasive treatment and coating treatments. The first portion of the combustion chamber is provided with an ignition device attached to a gun. The removable igniter is connected to fuel and oxygen sources and supplies the flame to the combustion chamber when the apparatus is started. After the gun is ignited, the igniter is removed.

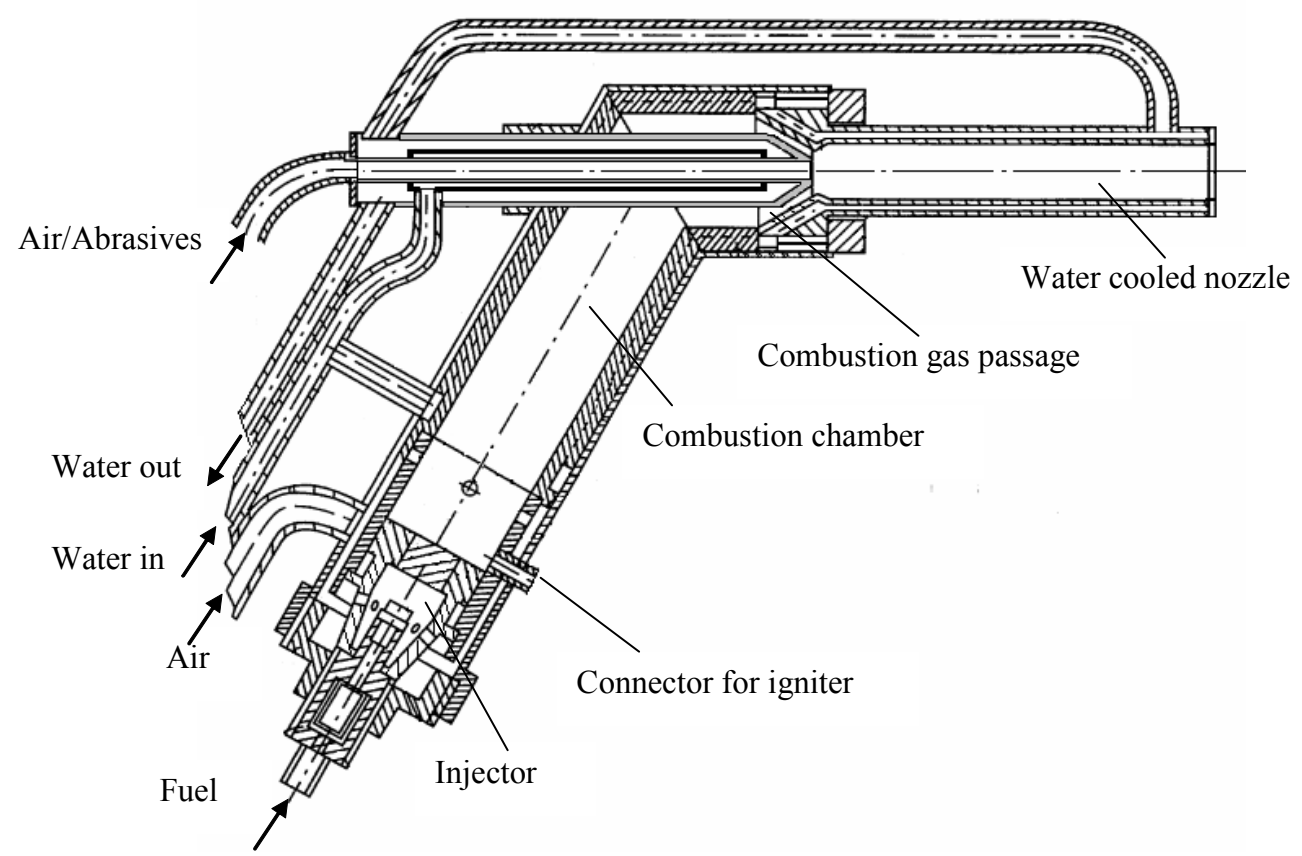

Figure 6: Diagram of Evdokimenko's HVAF thermal gun 
In the above design, the fuel mixes with cold air ultimately reducing the specific heat coefficient of the mixture. Another disadvantage of Evdokimenko's apparatus is that the fuelair mixture cannot be regulated, which is impractical. Furthermore, the apparatus requires oxygen for starting up and water for cooling during operation.

All of the above thermal guns have not found general application in abrasive blasting due to many factors, such as low cleaning rates, complexity, reliability etc. In general, a thermal gun should have a high efficiency under varying process conditions and provide sustainable performance over a long period of use. The ignition system of the thermal gun should be simple and reliable. The parameters of a thermal gun should be regulated and controlled with ease by an operator. It is suggested that, for economic and safety reasons, a thermal gun should utilize liquid fuels, such as diesel or paraffin, and not oxygen and gas or petrol. The requirement of water cooling complicates the design and operation of thermal guns and should be avoided.

\section{ADVANCED DESIGN OF THE THERMAL GUN}

\subsection{Combustion Chamber}

The main difference between the initial and advanced designs is in the way the fuel/air mixture is obtained (Fig. 7). The main portion of the oxidizer enters the combustion chamber in an opposite direction to the flow, providing more efficient mixing of fuel and air. Also, the fuel ejection passages are spiral grooves and not holes as in the initial design. This results in high efficiency of the combustion process and more power output.

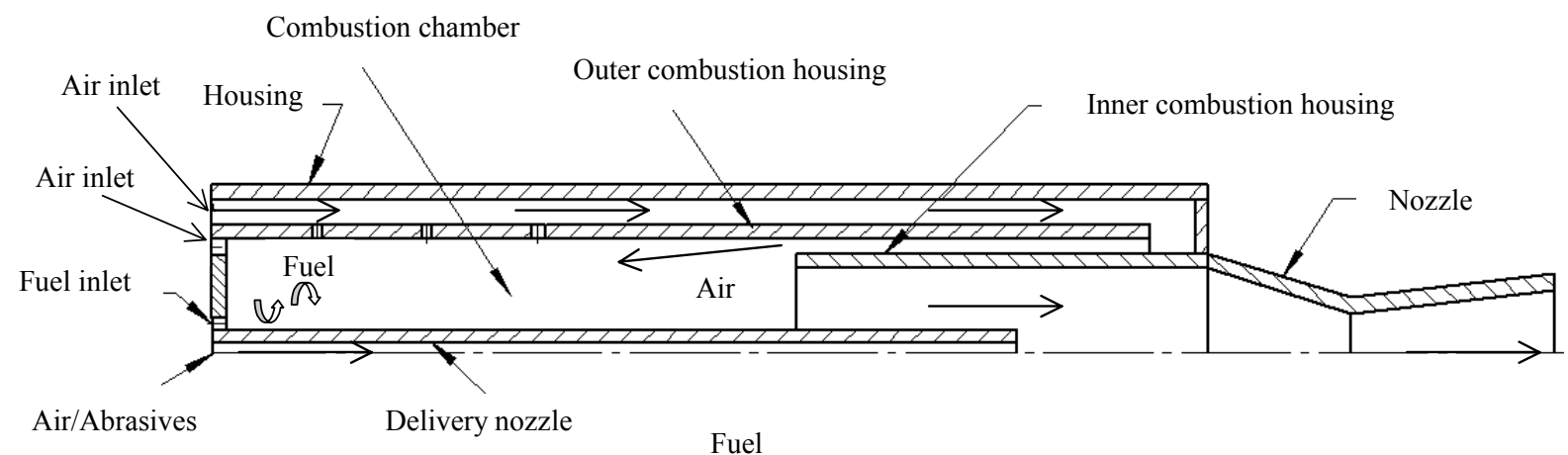

Figure 7: Schematic cross section of the improved design of the thermal gun

Referring to Figure 8, the compressed air for combustion is supplied through hole A. The main steam of the compressed air is first directed to annular passage, D. Then it goes through holes $\mathrm{E}$ in the outer combustion chamber housing, into spiral annular passage $\mathrm{F}$, and into the combustion chamber. The spiral grooves accelerate the airflow, which helps to penetrate the air deeper into the combustion chamber. A portion of this air enters the combustion chamber through the radial holes in the outer combustion housing. While going through the annular passages $\mathrm{D}$ and $\mathrm{F}$ the air temperature increases by absorbing the heat from the combustion housings. 


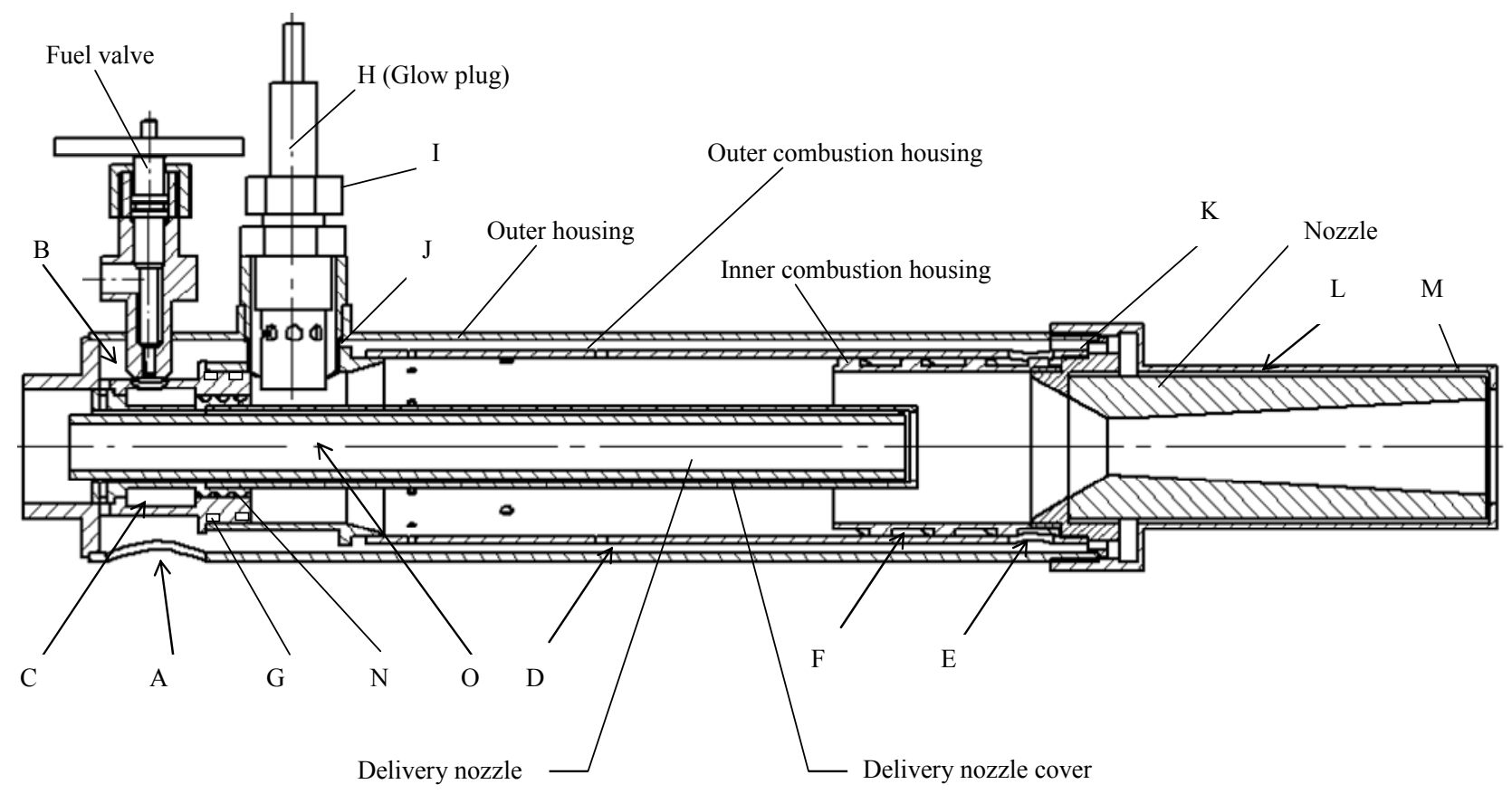

Figure 8: Diagram of the advanced design of the thermal-gun

In the advanced design, the fuel and air first mix in annular passage $C$ (Fig. 8). Then the fuel/air mixture is ejected through intersecting spiral grooves $\mathrm{N}$ of the injector. As the fuel goes though the spiral grooves it is further broken into fine droplets travelling at high velocity and having vortex movements. The fuel/air mixture stream and hot air meet in the middle of the combustion chamber. This is a final stage of fuel-air mixing. The main stream of the compressed air enters the combustion chamber in a direction opposite to the stream of fuel/air mixture creating turbulence, which results in a greater mixing of combustion components. The high quality of the fuel/air mixture provides complete combustion, leaving no carbon deposits inside the gun.

The other air stream is directed through spiral grooves G. The purpose of these grooves is to protect the outer combustion chamber housing walls from the fuel droplets depositing on it. Secondly this air also cools the housing.

The other feature of the new design is cooling of the nozzle. A small portion of the air from annular passage $\mathrm{D}$ goes through holes $\mathrm{K}$ in the nozzle holder. This air is used for cooling the nozzle by creating a forced airflow in annular passage $\mathrm{L}$ between the nozzle and the housing. The air escapes through holes $\mathrm{M}$ in the housing.

The abrasive/air mixture is supplied through the delivering nozzle (Fig 8). The flow is then directed through a converging-diverging nozzle. The concentricity of the delivery and the main nozzles is important for particles not to hit the sides of the main nozzle. Otherwise the main nozzle is worn unevenly and turbulence occurs in the flow.

The diameter of the delivery nozzle plays an important role in performance of the thermal gun. The bigger the internal diameter the more abrasive can pass through and, the performance is therefore better. The internal diameter of the delivery nozzle should be within 
9 to $13 \mathrm{~mm}$. However, there is a limitation on the external diameter of the nozzle, which is determined by the wall thickness of the nozzle. If the external diameter is too large it would occupy more of the combustion chamber space. Hence, there would be less space for the combustion process and less efficiency of the system, otherwise the size of the chamber must be increased.

The diameters of the delivery nozzle are dependent on a nozzle material and manufacturing processes. The delivery nozzle material must be heat resistant because the nozzle is inside of the area of high combustion temperatures. Also, the delivery nozzle material should be wear resistant as it delivers abrasives at relatively high speed, causing extensive wear.

In this research, two types of the delivery nozzle material were tested. These were stainless steel 310 and tungsten carbide. The former was a standard size pipe of half inch inside diameter. The latter one was a specially designed and pressed WC nozzle. The stainless steel delivery nozzles withstood the heat effect, but they wore out relatively quickly by abrasives. The tungsten carbide nozzles could not stand the high temperatures and oxidized on the outside surface. The solution was to place the tungsten carbide nozzle inside a cover of stainless steel pipe to protect the former from the heat. This is shown in the advanced design of the thermal gun (Fig. 8).

The distance between the exit of delivery nozzle and the main nozzle is $12-20 \mathrm{~mm}$, which was established experimentally. If the delivery nozzle is too close to the main nozzle it blocks the passage of the hot gases and the thermal gun chokes. If the delivery nozzle is too far from the main nozzle the back pressure is too high and abrasives slow down. The performance of blasting, in this case, is significantly reduced. Also small particles of abrasives are burnt because they stay in the hot gas flow longer.

\begin{tabular}{|l|c|}
\hline Parameter & Value \\
\hline Compressed air flow rate, $\mathrm{m}^{3} / \mathrm{h}$ & $200-320$ \\
\hline Fuel consumption, $1 / \mathrm{h}$ & $5,0-8,0$ \\
\hline Abrasive particles flow rate, $\mathrm{m}^{3} / \mathrm{h}$ & $0,10-0,15$ \\
\hline Maximum particle size, $\mathrm{mm}$ & 2,00 \\
\hline Pressure at the entry into the system, $\mathrm{MPa}$ & $0,3-0,9$ \\
\hline Inside diameter of the outer combustion chamber housing, mm & $40-48$ \\
\hline Wall thickness of the combustion chamber housing, mm & $2-2,5$ \\
\hline Length of the outer combustion chamber housing, $\mathrm{mm}$ & $190-220$ \\
\hline Diameter of critical section of the nozzle, mm & $14,0-16,0$ \\
\hline Included exit angle of the nozzle & $2^{\circ}-5^{\circ}$ \\
\hline Length of diverging part of the nozzle, mm & $70-100$ \\
\hline Internal diameter of the delivery nozzle, mm & $9,0-13,0$ \\
\hline External diameter of the delivery nozzle not more than, mm & 17 \\
\hline Distance from the exit of the delivery nozzle to the blasting nozzle, $\mathrm{mm}$ & $12-20$ \\
\hline
\end{tabular}

Table 1: Process operating specifications

The delivery nozzle ideally should also have a form of a Laval nozzle. This would decrease wall resistance and increase the velocity of the flow. However, the size, the material and the manufacturing constraints do not allow such a design of the delivery nozzle. For example, 
tungsten carbide or ceramic nozzles require a wall thickness of $3-4 \mathrm{~mm}$. At a nozzle length of $220 \mathrm{~mm}$ and a small wall thickness the manufacturing processes become too expensive.

As the result of tests, the specifications of the thermal gun were established. They are presented in Table 1.

\subsection{Ignition System}

A new method of igniting the thermal gun evolved in this research. The method is based on achieving a flame by means of a flame glow plug. Flame glow plugs are used for preheating diesel engines operating in cold regions.

Referring to Figure 8, flame glow plug $\mathrm{H}$ is positioned on the top of the gun. The heating element of the flame glow plug is positioned inside the combustion chamber. The fuel is supplied to the flame glow plug through fuel inlet I. An injector inside the flame glow plug dispenses a small quantity of fuel depending on the pressure in the fuel line. The conditions for the flame glow plug to ignite had to be similar to those on diesel engines. Therefore, holes $\mathrm{J}$ in the plug housing were made in order to provide passages for air for igniting a flame. If the air stream is too strong it cools down the heating element and no ignition takes place. On the other hand, too little air would not ignite a flame. The sizes and positions of the holes for the air passage were determined experimentally to achieve reliable ignition of the flame glow plug. Small amounts of fuel and air are supplied to the flame glow plug while it is heated up to $1000^{\circ} \mathrm{C}$. It takes $15-20$ seconds to ignite a flame. Once there is a flame inside the combustion chamber, the main air and fuel are simultaneously opened and combustion is achieved.

Figure 9 shows the thermal gun in operation, where rubber linings are removed from a flange.

\section{DESIGN OF THE CONTROL SYSTEM}

A control system of the thermal gun must provide a number of control functions for various working conditions and safety of operation. A difficulty arises from the fact that the thermal gun is a hand-held device. Therefore, the safety aspects and limitations on the weight significantly complicate the design. Also the equipment must be able to operate without electricity, in remote areas, on roads etc.

The control system requirements are as follows:

- The system should be fully automatic.

- The system should be controlled by a single operator.

- Combustion should be started before the abrasives flow is allowed.

- The fuel container should be depressurized in the off-sate.

- All the aspects of safety must be taken into account.

- The control system should be economically viable.

Figure 10 shows the thermo-abrasive system with the control valves. Valves V1, V2 and V3 control the airflow. Valves V1 and V2 are special valves for high volume flows, whereas valve V3 is a standard control valve. Valve V4 is a special shut-off valve, which is used for 
opening and closing of abrasives. Valve V5 is a standard shut-off valve, which is used for fuel.

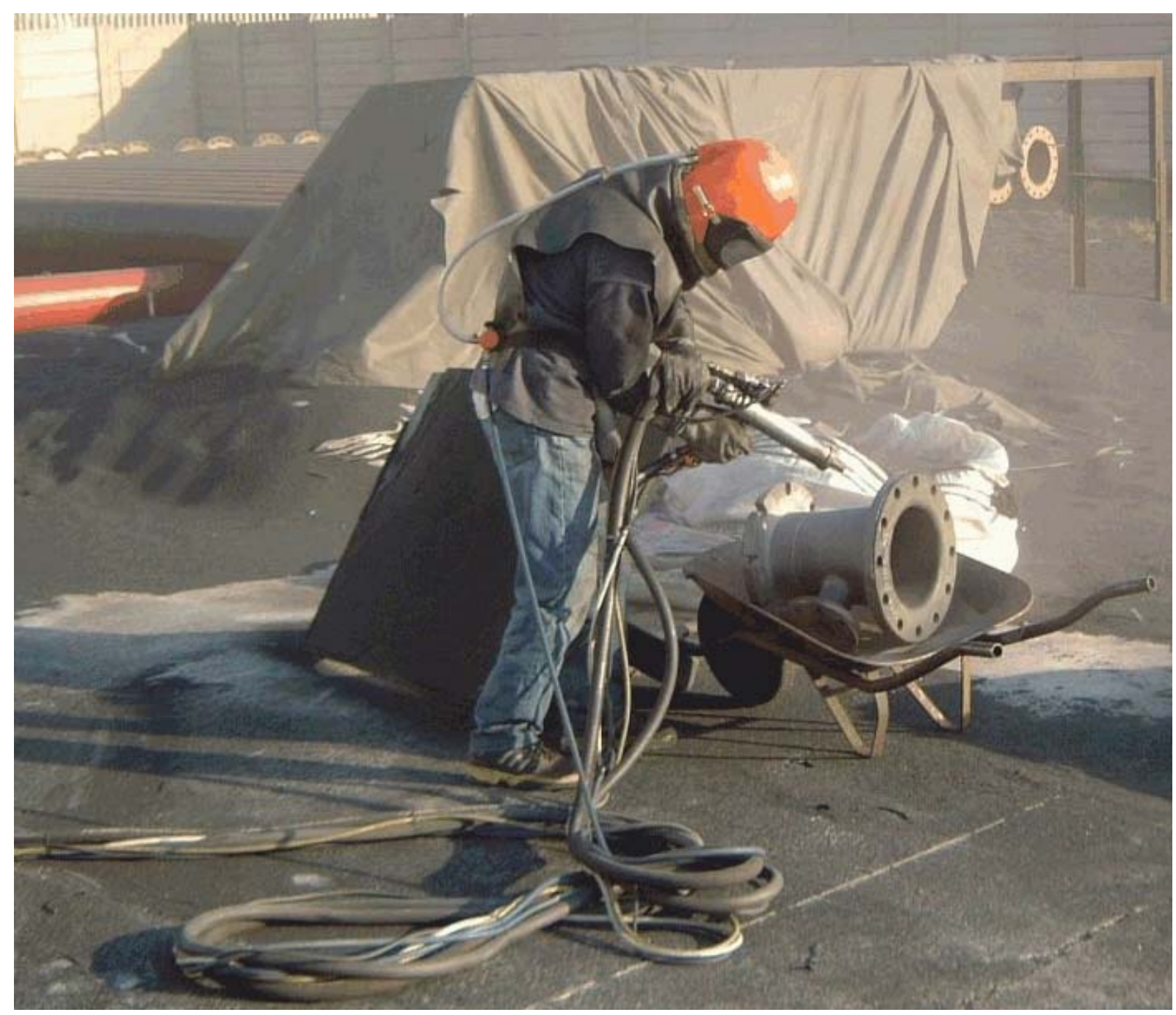

Figure 9: Thermal gun in operation

The control system is represented by the logic ladder diagram (Fig. 11) and the electropneumatic control circuit (Fig. 12). The logic sequence of the control system is described as following. When the "deadman" handle is pressed it triggers the control circuit. Solenoid 1 of valve V3 directs the compressed air to pressurize the fuel container. In the meantime Timer 1 switches on the power to the flame glow plug for 50 seconds, which is sufficient to heat the element.

After 20 seconds Timer 2 switches on solenoid 2 of valve V6, which directs the air to the restrictor and the pneumatic timer. The restrictor provides the airflow to ignite a flame. It is necessary to delay the airflow to the flame glow plug in order to achieve complete heating of the element. The purpose of the pneumatic timer is to provide a delay of $5-10$ seconds needed for a sustainable flame. After that the air is directed to valves V1, V2, V4 and V5, which simultaneously open the main air and fuel for combustion and abrasives. Valve V4 opens a passage for abrasives at the bottom of the pressure blast unit. 


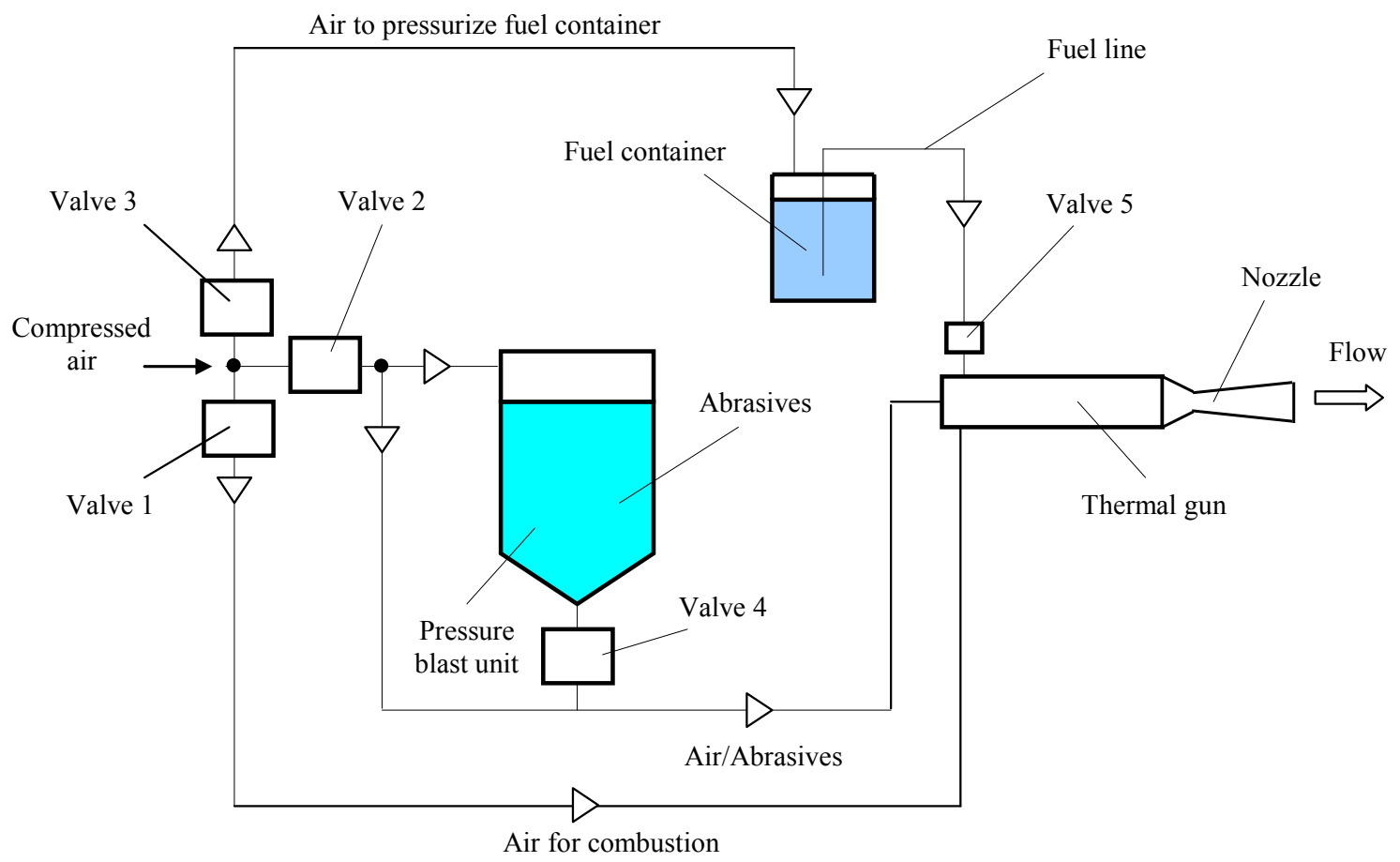

Figure 10: Diagram of the thermo-abrasive system with the control valves

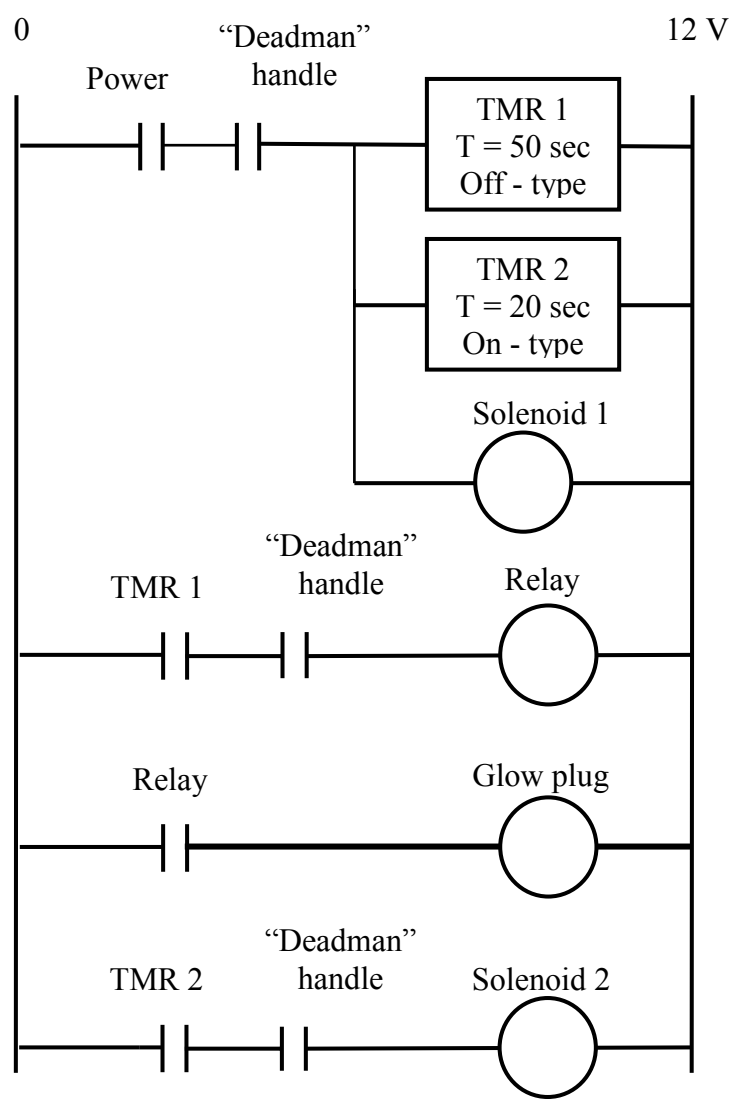

Figure 11: Logic ladder diagram 
If at any point in time the "deadman" handle is released the system shuts off. The control system is run on a car battery. Some compressors have $12 \mathrm{~V} \mathrm{DC}$ output, therefore they can be used for running the control system.

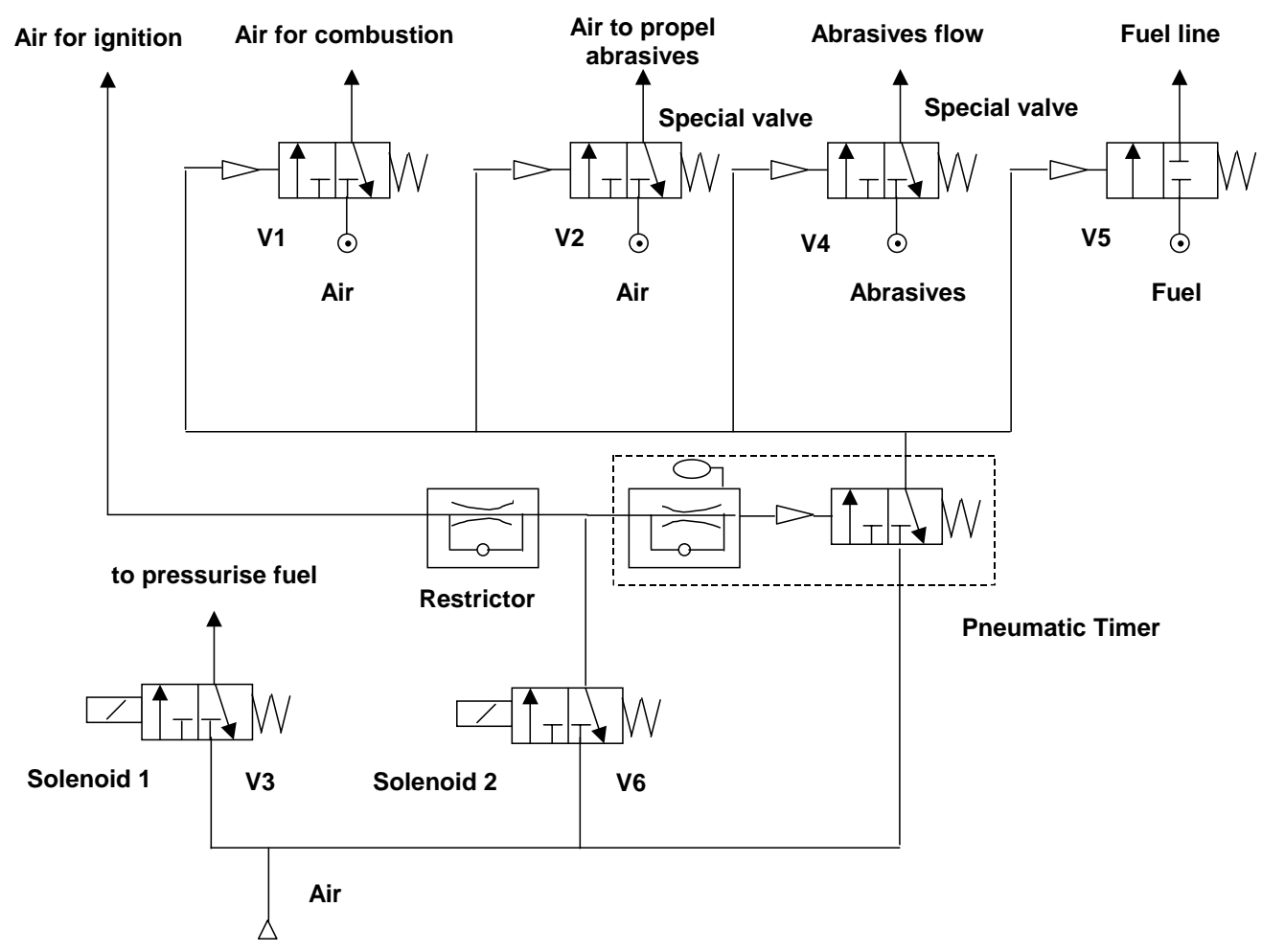

Figure 12: Electro-pneumatic control circuit

The thermo-abrasive system with the thermal gun on the stand is shown in Figure 13. The thermo-abrasive system consists of the thermal gun, the conventional blasting unit and the stand, which holds the fuel container, a battery and the control unit. If at any point in time the "deadman" handle is released, the system shuts off. The control system is run on a car battery. Some compressors have $12 \mathrm{~V} \mathrm{DC}$ output, therefore they can be used for running the control system.

\section{PERFORMANCE OF THE THERMAL GUN}

The rate of cleaning using the thermo-abrasive blasting is higher due to higher particle velocities. The high temperature jet also improves the quality of blasted surfaces as a result of a heat factor, which is responsible for removal of impurities, oil and moisture from surfaces. Also, due to the heat factor, the painting process can be done in cold weather, and in general the curing time of paint is reduced.

The thermal gun was successfully used for the removal of:

- metal coatings from dam gates at Vaal Dam

- rubber from mining equipment and pipes

- ceramic coatings from chemical equipment 
- polyurethane from components in the automotive industry

- hard scale from components after sand casting

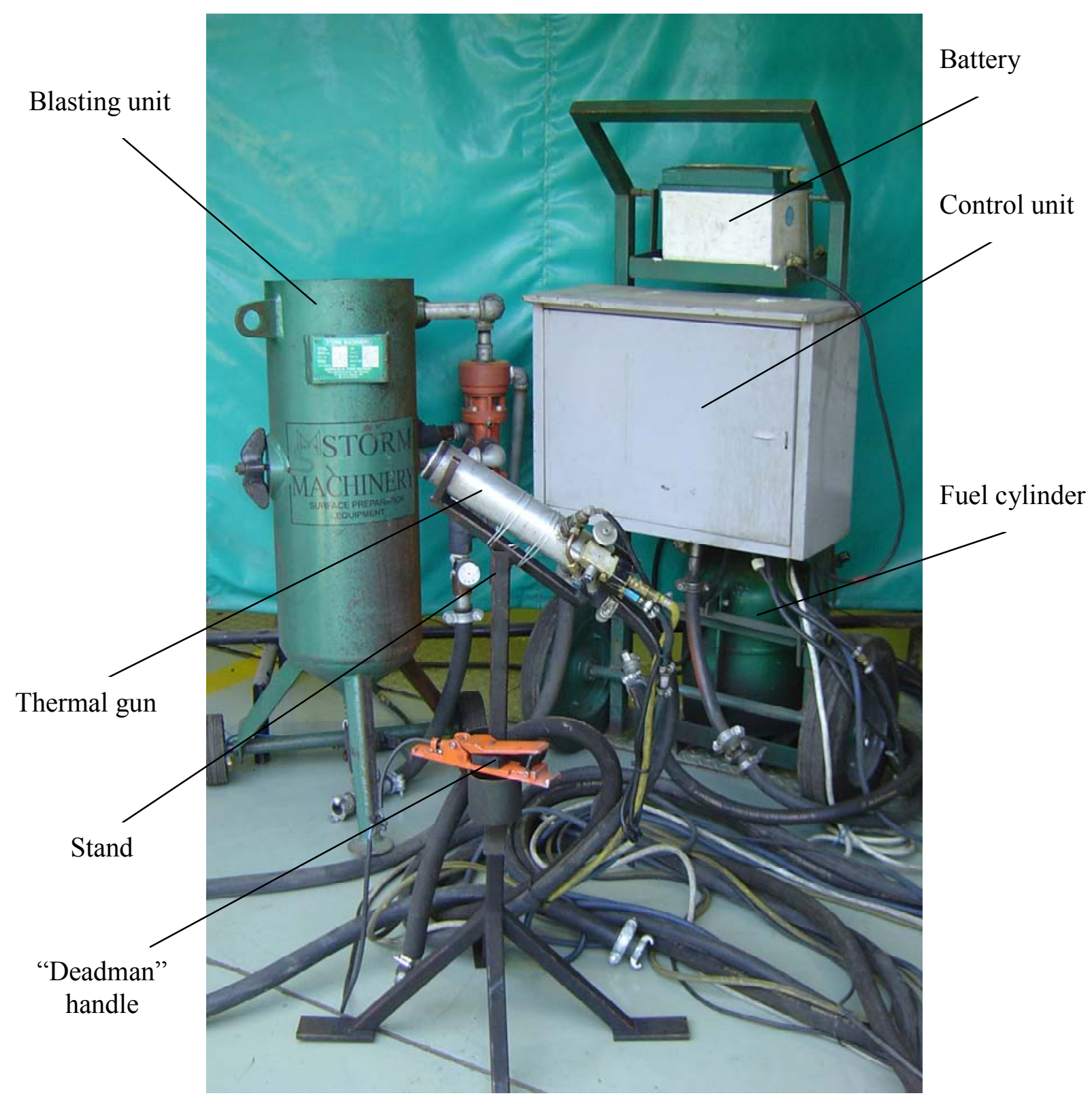

Figure 13: Thermo-abrasive system

In all the above applications the cleaning rate obtained was far better than with a conventional sand blasting system. In many instances, a conventional system failed to do the job at all.

For a comparison of cleaning rates, a steel surface of $1 \mathrm{~m}^{2}$ with mill scale was blasted to the Swedish cleanness specification of $\mathrm{Sa}=2,5$ ("whiteness" of a surface) using mineral slag of a $0,6 \mathrm{~mm}$ fraction size. Productivity comparison of thermo-abrasive blasting and conventional blasting is based on the tests performed by Storm Machinery (Pty.) Ltd and shown in Table 2. 


\begin{tabular}{|l|c|c|}
\hline Specifications & $\begin{array}{c}\text { Thermo-abrasive } \\
\text { blasting }\end{array}$ & $\begin{array}{c}\text { Conventional } \\
\text { abrasive blasting }\end{array}$ \\
\hline Pressure, bars & 5 & 7 \\
\hline Flow rate, CFM & 250 & 750 \\
\hline Cleaning Time of $1 \mathrm{~m}^{2}, \mathrm{~min}$ & 0,9 & 1,25 \\
\hline Quantity of abrasives, $\mathrm{kg}$ & 9 & 17 \\
\hline
\end{tabular}

Table 2: Productivity Comparison

The highest cleaning rate with the thermal gun was obtained at the dry docks in Durban, where $1 \mathrm{~m}^{2}$ of steel was cleaned in 30 seconds, using garnet. An economic comparison of the blasting methods showed that thermo-abrasive blasting is twice as economical as conventional blasting.

\section{ECONOMIC COMPARISON}

An economic comparison of the thermo and conventional blasting is based on the results of the tests shown in Table 2. A formula for the cost of cleaning is available from BLASTRITE (Pty.) Ltd, a supplier of blasting media. The formula has been modified to include the cost of paraffin for thermo-abrasive blasting. The cost of cleaning of $1 \mathrm{~m}^{2}$ is as follows:

Cleaning Cost $=\frac{\left(F A_{1}+L+A_{2}+C A_{3}\right)}{\text { Rate } \cdot D}+5 \%, \mathrm{R} / \mathrm{m}^{2}$

Where $F=$ the flow rate of abrasives, $t$ /hour,

$A_{1}=$ the abrasive cost, $\mathrm{R} / \mathrm{t}$,

$L=$ the labour cost, $\mathrm{R} /$ hour,

$A_{2}=$ the air compressor cost, $\mathrm{R} /$ hour,

Rate $=$ rate of cleaning, $\mathrm{m}^{2} /$ hour,

$D=$ degree of cleanliness, $\mathrm{D}=1$ for Sa3 and $\mathrm{D}=1,75$ for $\mathrm{Sa} 2,5$

$C=$ the consumption of paraffin, $1 /$ hour,

$A_{3}=$ the paraffin cost, $\mathrm{R} /$ litre.

\begin{tabular}{|l|c|c|}
\hline Parameters & Thermal Gun & Conventional Systems \\
\hline $\mathrm{R}=$ rate of cleaning, $\mathrm{m}^{2} /$ hour & 65 & 48 \\
\hline $\mathrm{F}=$ the flow rate of abrasives, $\mathrm{t} /$ hour & 0,59 & 0,82 \\
\hline $\mathrm{A}_{1}=$ the abrasive cost, $\mathrm{R} / \mathrm{t}$ & 400 & 400 \\
\hline $\mathrm{L}=$ the labour cost, $\mathrm{R} /$ hour & 20 & 20 \\
\hline $\mathrm{A}_{2}=$ the air compressor cost, $\mathrm{R} /$ hour & 70 & 200 \\
\hline $\mathrm{D}=$ degree of cleanliness for SA3, & 1 & 1 \\
\hline $\mathrm{C}=$ the consumption of paraffin, $1 /$ hour & 6 & - \\
\hline $\mathrm{A}_{3}=$ paraffin cost, $\mathrm{R} /$ litre & 3,7 & - \\
\hline Additional cost & $5 \%$ & $5 \%$ \\
\hline Cleaning Cost of $1 \mathrm{~m}^{2}, \mathrm{R} / \mathrm{m}^{2}$ & $\mathrm{R} \mathrm{5,6}$ & $\mathrm{R} 12,0$ \\
\hline
\end{tabular}

Table 3: Cost Comparison 
The results of the calculations are shown in Table 3. It can be seen that thermo-abrasive blasting is at least $50 \%$ more economical than conventional blasting with $25 \%$ increase in productivity. In order to match this performance, a conventional abrasive blasting system must use a $19 \mathrm{~mm}$ nozzle, which requires a $1000 \mathrm{CFM}$ flow rate at 12 bar pressure, and use at least double the amount of sand.

\section{CONCLUSION}

The new design of the thermal gun proved to be more efficient and versatile than the initial design. The new method of mixing air and fuel increases power output. The advanced thermal gun has outperformed the initial thermal gun in all tests. The new ignition method using a flame glow plug proved to be reliable and consistent.

The developed control system allows to operate the thermal gun in an automatic mode. This can be used in various applications of thermo-abrasive blasting. For example, a thermal gun can be used in shot blasting machines instead of impellers. Another potentially important application of the thermal gun is for blasting inside of pipes prior to coating or rubberising. Thermal blasting removes impurities, which typically cause failures of rubber linings.

This study of the thermo-abrasive gun can be taken further to thermal spraying applications. The existing thermal spraying process is expensive due to the cost of equipment and consumables. The thermo-abrasive gun is much cheaper to run because it uses only compressed air and diesel. The initial trials of thermal spraying using the thermal gun described in this study, showed good results regarding speed and quality of spraying.

\section{REFERENCES}

[1] Browning, J. 1983. High Velocity Flame Jet Internal Burner for Blast Cleaning and Abrasive Cutting. US Patent 4,384,434.

[2] Galchenko, L. et al. 1982. Method of thermal treatment of components. N 967144, Krivoy Rog: Krivoy Rog Gorny Institute.

[3] Kotov, S., Gorlach, I.A., Dubetsky, I. 2000. Materials treatment apparatus and process. South African Patent 2000/2862.

[4] Gorlach, I.A. 2002. High Velocity Thermal Gun for Surface Preparation and Treatment. South African Journal for Industrial Engineering, 13(1), pp. $131-143$.

[5] Evdokimenko, Y. et al. 1997. High Velocity Flame Jet Apparatus for Thermoabrasive Cutting or Cleaning or for the Application of Protective Coatings. US Patent $5,607,342$.

[6] Mostaghimi, J. et al. 2003. Modelling thermal spray coating processes: a powerful tool in design and optimization. Surface and Coatings Technology $163-164$, pp. $1-11$.

[7] Turns, S.R. 2000. An Introduction to Combustion. $2^{\text {nd }}$ Ed. Boston: McGraw Hill, $676 \mathrm{p}$.

[8] Rauenzahn, R.M., Tester, J.W. 1991. Numerical simulation and field testing of flame-jet thermal spallation drilling. Model development, Int. J. Heat Trans., 3493, pp. 895-808.

[9] Weibull, W. 1939. A statistical theory of the strength of materials. Proc Roy Swedish Inst Engng Res; 151, pp. 1 -45. 
[10] Wilkinson, M.A., Tester, J.W. 1993. Experimental measurement of surface temperatures during flame-jet induced thermal spallation. Rock Mech. Rock Engng. 26(1), pp.29-62. 